\title{
CRITICAL SUCCESS FACTORS \\ IN ERP SYSTEM ADOPTION: COMPARATIVE ANALYSIS OF THE PRIVATE AND THE PUBLIC SECTOR
}

\author{
Laslo Seres, Pere Tumbas, Predrag Matkovic, Marton Sakal
}

\section{Introduction}

Enterprise Resource Planning (ERP) systems are enterprise-wide information systems that integrate and control the complete range of processes and functions, in order to provide a holistic view of the business from a single information and information technology (IT) architecture (Klaus, Rosemann, \& Gable, 2000), enabling organizations to manage efficient and effective use of their resources by using a complete, integrated, packaged software solution and a common central database for the organization's information-processing needs (Al-Fawaz, Eldabi, \& Naseer, 2010). By adopting an ERP system, organizations are looking for a better use of their own resources in order to raise their own efficiency, which can be jeopardized by high costs associated with ERP implementation, staff training, as well as maintaining and aligning the system with the needs of the organization (Jáčová, Brabec, \& Horák, 2013).

A successful adoption of an ERP system requires extensive efforts in the preimplementation, implementation and postimplementation period, as to ensure a high level of acceptance and use of the ERP system by the organization and its employees. These efforts are related to Critical Success Factors (CSFs) which are usually treated as "...the limited number of areas in which results, if they are satisfactory, will ensure successful competitive performance for the organization" (Rockart, 1979). They are believed to be the most influential forces in ERP success and therefore must be monitored and controlled (Sun, Ni, \& Lam, 2015) during an ERP adoption process.

A majority of studies that concern ERP systems adoption are focused on the main CSFs and methodologies for ERP implementation. Over the last decade, several authors have published studies devoted to the identification of critical issues or success factors of ERP adoption (Finney \& Corbett, 2007; Ram \& Corkindale, 2014; Shaul \& Tauber, 2013; Sun et al., 2015). In the analyzed studies, the authors have identified over 80 CSFs for ERP adoption (Sun et al., 2015), and proposed several criteria for their classification. According to Ngai et al. (2008), diverse subsets of identified CSFs, rather than a comprehensive set of similar factors, are a result of different limited case studies and research settings, as well as different geographic areas (countries) where studies had been conducted.

Adoption of ERP systems is greatly influenced by certain organizational characteristics, commonly referred to as business factors. In contrast to the very extensive research on differences in implementation of ERP systems between SMEs and large organizations, the literature devoted to analysis of differences between private and public sector organizations in terms of ERP adoption and its CSFs is quite scarce. Emergence of such studies, even in a small number, can be ascribed to evident differences between private and public sector organizations. In contrast to market-oriented organizations, public sector organizations tend to be more complex (Řepa, 2014), and the requirements for information transparency oblige them to manage large quantities of specific types of data (Mohelská \& Sokolová, 2017). It is interesting, but not surprising, that researchers who analyzed ERP adoption CSFs usually relied on samples composed from organization of the same type. The majority of researchers were focused on private organizations; however, there is a noticeable 
increase of studies focusing on public organizations (Mengistie, Heaton, \& Rainforth, 2013; Ziemba \& Oblak, 2013; Leandro, Mexas, \& Drumond, 2017). The number of authors who used samples comprised of both private and public organizations is significantly smaller. Ahmed and Khan (2013), Alves and Matos (2013) and Wingreen et al. (2014) are among the authors who carried out immediate comparative analyses of ERP adoptions in the two sectors.

The aim of this paper is to further reduce this knowledge gap and allow better understanding of the differences in ERP adoption between the public and the private sector. First, we wanted to compare the perceived significance, as well as the perceived success, in terms of widely accepted, common CSFs in organizations from the two sectors. Second, we wanted to investigate whether there are certain areas that appear to be much more critical in one of the two sectors. This would provide useful information regarding the allocation of resources, as well as certain segments that require special attention when an ERP solution is implemented in a particular sector. As a result of extensive analysis of relevant literature, we compiled a set of CSFs that were subsequently evaluated by reputable Serbian private and public organizations, in terms of CSFs' significance and fulfillment. By prioritizing and ranking relevant CSFs, we wanted to determine to what extent does the perception of ERP adoption CSFs differ between the sectors.

The research questions (RQ) we addressed in this paper are as follows:

- RQ1: To what extent do private and public organizations differ in their assessments of ERP adoption CSFs' significance?

- RQ2: To what extent do private and public organizations differ in their assessments of ERP adoption CSFs' fulfillment?

- RQ3: Are there any specific areas that can be identified as significantly more challenging in one of the two compared sectors?

We believe that answering these questions will provide a much better insight into the presumed differences in ERP adoption between private and public organizations and thereby contribute to the success of future "ERP adventures".

Following the introduction, the paper includes the following sections: Section 1 provides insight into state of the affairs through a detailed review of relevant literature; Section 2 is devoted to the description of the research methodology used; Section 3 contains the research results; Section 4 presents discussion and practical implications of obtained results; finally, Section 5 gives general conclusions, as well as an overview of limitations and directions for further research.

\section{Literature Overview}

The literature suggests various criteria for CSFs classification, and different authors identify CSFs at different level of granularity (it is not rare that different authors use different terms to refer to the same CSF or state something as a single CSF, while others break it down in two or more CSFs). Issues and CSFs identified in these studies range from those related to organizational and project management to those related to implementation strategy and human resources. ERP adoption CSFs have already been investigated in numerous organizations that vary in size, business area, type of ownership, level of development of the national economy, and other characteristics.

Authors of comparative analyses of the ERP systems adoption process in private and public organizations state many differences, including ones in national and organizational cultures, which are recognized as one of the most important. Complex organizational structures inherent to public organizations, which affect the possibility of determining appropriate process owners due to fragmented departments (Wagner \& Antonucci, 2009), can also be identified as a significant difference. For this reason, adoption of ERP systems in public organizations does not represent a source of competitiveness, as often numerous organizational units share applications and competencies with each other. Project teams are large, due to a vast number of representatives from many departments and divisions. The funding process is complex, and resources are allocated through budgetary processes, not by market mechanisms, making it more challenging than in private organizations. Investment planning is influenced by political pressure, and it is mostly oriented on short-term period.

In their analysis of ERP systems adoption in the two sectors, Alves and Matos (2013) highlight the difference in the number 
of implemented modules, as well as the difference in the importance of particular modules, attributed to the specificities of the public sector. The authors concluded that the number of implemented modules is smaller in the public sector, and that the deployment time is shorter. Organizations operating in the public sector have multiple, often intangible and/or conflicting goals, as well as numerous different stakeholders with competing interests (Campbell, McDonald, \& Sethibe, 2009). Finally, it is very difficult to identify "best business practices" among public organizations, in order to utilize certain experiences.

The previously mentioned specifics of public organizations in relation to the ERP systems adoption process can serve as a basis for identifying the most important CSFs for ERP systems adoption. As a general conclusion to the literature review, we can state that most studies still remain limited to sole identification of these CSFs, not addressing their individual relevance in any way. A small number of research papers focused on the analysis of CSFs' significance did not discriminate surveyed organizations, i.e. did not compare subsets of organizations from the private sector with the ones from the public sector. Moreover, comparative analyses of ERP application among public and private organizations are mostly limited to analyses of implemented modules (number, content, implementation times), specifics of business processes in each sector and identification of some specific CSFs. A research concerned with comparative analysis of significance and fulfillment of common CSFs in the two sectors would provide a different outlook in the research on ERP systems adoption.

\section{Research Methodology}

The methodology developed for this research comprises five stages: analysis of the literature, creating the CSF pool, instrument development, data collection, data analysis and interpretation of results.

\subsection{Analysis of the Literature}

Analysis of the literature was carried out on academic peer-reviewed articles, published in academic journals between 2006 and 2017, which were gathered from selected bibliographic databases (Web of Science and Scopus), an aggregator (EBSCO Business Source Premier), and a publisher's database (Emerald Group Publishing and Wiley). Papers published in AIS conference collections from prominent scientific conferences ICIS, AMCIS, $\mathrm{ECIS}$ and PACIS were analysed as well. The listed sources were queried with the purpose of identifying preceding studies. Descriptors used for querying for matches in paper title, abstract or paper topics were defined in accordance with the research problem and previously set research questions. The following descriptors

\section{Tab. 1: Search results for the selected terms in academic databases}

\begin{tabular}{|c|c|c|c|c|c|c|c|c|c|}
\hline \multirow{3}{*}{$\begin{array}{l}\text { Bibliographic } \\
\text { databases, } \\
\text { aggregator, } \\
\text { publisher }\end{array}$} & \multirow{3}{*}{ Provider } & \multicolumn{8}{|c|}{ Descriptors } \\
\hline & & \multicolumn{2}{|c|}{$\begin{array}{c}\text { „Enterprise } \\
\text { Resource Planning“ } \\
+ \\
\text { "Critical Success } \\
\text { Factors" } \\
\end{array}$} & \multicolumn{2}{|c|}{$\begin{array}{c}\text { ERP } \\
+ \\
\text { "Critical Success } \\
\text { Factors“ }\end{array}$} & \multicolumn{2}{|c|}{$\begin{array}{c}\text { „Enterprise } \\
\text { Resource Planning“ } \\
+ \\
\text { CSF }\end{array}$} & \multicolumn{2}{|c|}{$\begin{array}{c}\text { ERP } \\
+ \\
\text { CSF }\end{array}$} \\
\hline & & Title & Abstract & Title & Abstract & Title & Abstract & Title & Abstract \\
\hline Web of Science & \begin{tabular}{|l|} 
Thomson \\
Reuters
\end{tabular} & 10 & 326 & 36 & 462 & 0 & 25 & 1 & 54 \\
\hline Scopus & Elsevier & 16 & 284 & 46 & 233 & 1 & 122 & 11 & 110 \\
\hline $\begin{array}{l}\text { EBSCO Business } \\
\text { Source Premier }\end{array}$ & $\begin{array}{l}\text { EBSCO } \\
\text { publishing }\end{array}$ & 10 & 62 & 26 & 82 & 0 & 34 & 5 & 45 \\
\hline $\begin{array}{l}\text { Emerald Group } \\
\text { Publishing }\end{array}$ & $\begin{array}{l}\text { Emerald Group } \\
\text { Publishing }\end{array}$ & 2 & 39 & 10 & 46 & 0 & 2 & 1 & 9 \\
\hline Wiley & Wiley & 1 & 5 & 0 & 10 & 1 & 1 & 0 & 2 \\
\hline
\end{tabular}


were chosen as search criteria: "Enterprise Resource Planning", "Critical Success Factors", ERP, and CSF (Tab. 1).

The initial list of published studies, obtained as a result of conducted searches, encompassed a total of $\mathbf{7 3 2}$ research articles. The result list was compiled by combining aforementioned descriptors, after which the papers were subject to preliminary analysis aimed at determining their significance for the research problem and research questions. The focus of the detailed analysis was on discovering CSFs of ERP systems adoption, classifying them, and preparing for further analyses. After a thorough examination, 29 research papers related to the research objective were selected.

\subsection{Creating the CSF Pool}

As a result of an extensive literature review, we have put together a comprehensive list of CSFs, which correspond with different CSF dimensions or categories proposed in the literature. Having analyzed the frequency of their occurrence, we reduced the list to 30 CSFs most frequently mentioned in the literature. Tab. 2 outlines the frequency analysis of the 30 CSFs chosen for this study.

\section{Tab. 2: Frequency analysis of the CSFs included in the final CSF pool (Part 1)}

\section{CSF and references}

CSF 1. Completed feasibility study: Finney \& Corbett, 2007; Nah \& Delgado, 2006; Ngai et al., 2008; Shaul \& Tauber, 2012.

CSF 2. Clearly defined goal(s) of introduction and scope of implementation project: Ahmad \& Cuenca, 2013; Ahmed \& Khan, 2013; Al-Fawaz et al., 2010; Amini \& Sadat, 2013; Ansarinejad et al., 2011; Dezdar \& Sulaiman, 2009; Doom et al., 2010; Finney \& Corbett, 2007; Ganesh \& Mehta, 2010; Sánchez \& Pérez-Bernal, 2007; King \& Burgess, 2006; Kronbichler, Ostermann, \& Staudinger, 2009; Nah \& Delgado, 2006; Ngai et al., 2008; Norton, 2015; Remus, 2007; Saade \& Nijher, 2016; Agaoglu et al., 2015; Tarhini et al., 2015.

CSF 3. Compliance of business and information visions and objectives: Dezdar \& Sulaiman, 2009; Ngai et al., 2008; Shaul \& Tauber, 2012; Gupta et al., 2014; Tarhini et al., 2015; Françoise et al., 2009.

CSF 4. Project coordinator or manager competency level: Ahmad \& Cuenca, 2013; Norton, 2015; Françoise et al., 2009; Rajnoha et al., 2014.

CSF 5. Project sponsor existence and competencies: Ahmad \& Cuenca, 2013; Ahmed \& Khan, 2013; Al-Fawaz et al., 2010; Amini \& Sadat, 2013; Dezdar \& Sulaiman, 2009; Finney \& Corbett, 2007; Ganesh \& Mehta, 2010; Sánchez \& Pérez-Bernal, 2007; King \& Burgess, 2006; Kronbichler et al., 2009; Nah \& Delgado, 2006; Ngai et al., 2008; Norton, 2015; Remus, 2007; Shaul \& Tauber, 2012.

CSF 6. Project team structure and competencies: Ahmad \& Cuenca, 2013; Ahmed \& Khan, 2013; Ansarinejad et al., 2011; Doom et al., 2010; Finney \& Corbett, 2007; Ganesh \& Mehta, 2010; Sánchez \& Pérez-Bernal, 2007; Nah \& Delgado, 2006; Ram \& Corkindale, 2014; Remus, 2007; Norton, 2015; Saade \& Nijher, 2016; Agaoglu et al., 2015; Françoise et al., 2009; Rajnoha et al., 2014.

CSF 7. Presence of full time members on the project: Nah \& Delgado, 2006; Ngai et al., 2008; Shaul \& Tauber, 2012; Rajnoha et al., 2014.

CSF 8. Project methodology: Ahmad \& Cuenca, 2013; Amini \& Sadat, 2013; Ansarinejad et al., 2011; Doom et al., 2010; Ngai et al., 2008; Norton, 2015; Agaoglu et al., 2015; Tarhini et al., 2015; Rajnoha et al., 2014; Peci \& Vazan, 2014.

CSF 9. Implemented performance indicator control and measurement: Ahmad \& Cuenca, 2013; Al-Fawaz et al., 2010; Dezdar \& Sulaiman, 2009; Finney \& Corbett, 2007; Ganesh \& Mehta, 2010; Nah \& Delgado, 2006; Ngai et al., 2008; Shaul \& Tauber, 2012; Saade \& Nijher, 2016; Gupta et al., 2014.

CSF 10. Completed business process redesign: Ahmad \& Cuenca, 2013; Ahmed \& Khan, 2013; Al-Fawaz et al., 2010; Amini \& Sadat, 2013; Finney \& Corbett, 2007; Ganesh \& Mehta, 2010; Sánchez \& Pérez-Bernal, 2007; King \& Burgess, 2006; Kronbichler et al., 2009; Nah \& Delgado, 2006; Ngai et al., 2008; Remus, 2007; Norton, 2015; Saade \& Nijher, 2016; Agaoglu et al., 2015; Tarhini et al., 2015; Françoise et al., 2009; Peci \& Vazan, 2014. 


\section{Tab. 2: Frequency analysis of the CSFs included in the final CSF pool (Part 2)}

CSF 11. Completed staff education on redesigned business processes: Ahmad \& Cuenca, 2013; Ahmed \& Khan, 2013; Al-Fawaz et al., 2010; Doom et al., 2010; Finney \& Corbett, 2007; Ganesh \& Mehta, 2010; Ngai et al., 2008; Remus, 2007; Shaul \& Tauber, 2012; Sommer, 2011.

CSF 12. Customization of software solutions to business processes: Ahmad \& Cuenca, 2013; Ahmed \& Khan, 2013; Al-Fawaz et al., 2010; Amini \& Sadat, 2013; Ansarinejad et al., 2011; Ngai et al., 2008; Shaul \& Tauber, 2012; Gupta et al., 2014; Peci \& Vazan, 2014.

CSF 13. Readiness of the organization and individuals to undergo changes: Ahmad \& Cuenca, 2013; Amini \& Sadat, 2013; Ansarinejad et al., 2011; Dezdar \& Sulaiman, 2009; Doom et al., 2010; Finney \& Corbett, 2007; King \& Burgess, 2006; Kronbichler et al., 2009; Ngai et al., 2008; Saade \& Nijher, 2016; Françoise et al., 2009.

CSF 14. Effective structural change management in the organization: Ahmed \& Khan, 2013; AlFawaz et al., 2010; Dezdar \& Sulaiman, 2009; Doom et al., 2010; Finney \& Corbett, 2007; Ganesh \& Mehta, 2010; King \& Burgess, 2006; Kronbichler et al., 2009; Ngai et al., 2008; Shaul \& Tauber, 2012; Norton, 2015; Gupta et al., 2014; Tarhini et al., 2015; Françoise et al., 2009; Peci \& Vazan, 2014.

CSF 15. Effective communication between individuals and groups in the organization: Ahmad \& Cuenca, 2013; Ahmed \& Khan, 2013; Al-Fawaz et al., 2010; Amini \& Sadat, 2013; Ansarinejad et al., 2011; Dezdar \& Sulaiman, 2009; Doom et al., 2010; Finney \& Corbett, 2007; Ganesh \& Mehta, 2010; Sánchez \& Pérez-Bernal, 2007; King \& Burgess, 2006; Kronbichler et al., 2009; Nah \& Delgado, 2006; Ngai et al., 2008; Remus, 2007; Shaul \& Tauber, 2012; Norton, 2015; Saade \& Nijher, 2016; Gupta et al., 2014.

CSF 16. Existence of top management support, involvement and commitment: Ahmad \& Cuenca, 2013; Ahmed \& Khan, 2013; Al-Fawaz et al., 2010; Amini \& Sadat Safavi, 2013; Ansarinejad et al., 2011; Dezdar \& Sulaiman, 2009; Doom et al., 2010; Finney \& Corbett, 2007; Ganesh \& Mehta, 2010; Sánchez \& Pérez-Bernal, 2007; King \& Burgess, 2006; Kronbichler et al., 2009; Nah \& Delgado, 2006; Ngai et al., 2008; Remus, 2007; Shaul \& Tauber, 2012; Saade \& Nijher, 2016; Gupta et al., 2014; Agaoglu et al., 2015; Tarhini et al., 2015; Françoise et al., 2009.

CSF 17. Use of steering committee for project activity control: Ahmad \& Cuenca, 2013; Ahmed \& Khan, 2013; Ngai et al., 2008; Remus, 2007; Shaul \& Tauber, 2012; Norton, 2015.

CSF 18. Implementation team structure and competence: Al-Fawaz et al., 2010; Amini \& Sadat, 2013; Dezdar \& Sulaiman, 2009; Doom et al., 2010; Finney \& Corbett, 2007; Sánchez \& Pérez-Bernal, 2007; Nah \& Delgado, 2006; Remus, 2007; Shaul \& Tauber, 2012; Tarhini et al., 2015; Peci \& Vazan, 2014.

CSF 19. Involvement of end users in ERP adoption and implementation activities: Al-Fawaz et al., 2010; Dezdar \& Sulaiman, 2009; Finney \& Corbett, 2007; Ganesh \& Mehta, 2010; Nah \& Delgado, 2006; Ngai et al., 2008; Shaul \& Tauber, 2012; Gupta et al., 2014; Françoise et al., 2009.

CSF 20. Existence of interdepartmental cooperation between organization segments: Ahmad \& Cuenca, 2013; Ahmed \& Khan, 2013; Dezdar \& Sulaiman, 2009; King \& Burgess, 2006; Ngai et al., 2008; Remus, 2007; Shaul \& Tauber, 2012; Norton, 2015; Saade \& Nijher, 2016; Agaoglu et al., 2015; Tarhini et al., 2015.

CSF 21. Existence of appropriate information infrastructure and competence for use of information technologies: Ahmad \& Cuenca, 2013; Ahmed \& Khan, 2013; Finney \& Corbett, 2007; Ganesh \& Mehta, 2010; Kronbichler et al., 2009; Ngai et al., 2008.

CSF 22. Completion of system testing and conversion: Ahmad \& Cuenca, 2013; Ahmed \& Khan, 2013; Ansarinejad et al., 2011; Dezdar \& Sulaiman, 2009; Doom et al., 2010; Finney \& Corbett, 2007; Ganesh \& Mehta, 2010; Sánchez \& Pérez-Bernal, 2007; Kronbichler et al., 2009; Nah \& Delgado, 2006; Ngai et al., 2008; Remus, 2007; Shaul \& Tauber, 2012; Peci \& Vazan, 2014.

CSF 23. Representation of the key features of ERP system and choice of ERP solutions based on these: Ahmad \& Cuenca, 2013; Ahmed \& Khan, 2013; Al-Fawaz et al., 2010; Dezdar \& Sulaiman, 2009; Doom et al., 2010; Finney \& Corbett, 2007; Ganesh \& Mehta, 2010; Kronbichler et al., 2009; Remus, 2007; Norton, 2015; Gupta et al., 2014; Agaoglu et al., 2015. 


\section{Tab. 2: Frequency analysis of the CSFs included in the final CSF pool (Part 3)}

CSF 24. Possibility of integration of the implemented ERP solution with other software solutions in the organization: Ahmad \& Cuenca, 2013; Nah \& Delgado, 2006; Shaul \& Tauber, 2012.

CSF 25. Ease of use of ERP solutions and level of users' acceptance: Ngai et al., 2008.

CSF 26. Number of ERP modules and dynamics of their implementation: Ahmad \& Cuenca, 2013; Nah \& Delgado, 2006; Ngai et al., 2008; Shaul \& Tauber, 2012; Norton, 2015.

CSF 27. ERP vendor selection: Ansarinejad et al., 2011; Finney \& Corbett, 2007; Ganesh \& Mehta, 2010; Sánchez \& Pérez-Bernal, 2007; Nah \& Delgado, 2006; Ngai et al., 2008; Shaul \& Tauber, 2012; Saade \& Nijher, 2016; Agaoglu et al., 2015; Tarhini et al., 2015; Peci \& Vazan, 2014.

CSF 28. User training scope and quality: Ahmed \& Khan, 2013; Al-Fawaz et al., 2010; Ansarinejad et al., 2011; Dezdar \& Sulaiman, 2009; Doom et al., 2010; Ganesh \& Mehta, 2010; Sánchez \& PérezBernal, 2007; Nah \& Delgado, 2006; Ngai et al., 2008; Remus, 2007; Shaul \& Tauber, 2012; Norton, 2015; Gupta et al., 2014; Agaoglu et al., 2015; Tarhini et al., 2015; Peci \& Vazan, 2014.

CSF 29. Extent of use and scope of responsibility of consultants: Ahmad \& Cuenca, 2013; Ahmed \& Khan, 2013; Al-Fawaz et al., 2010; Amini \& Sadat, 2013; Ansarinejad et al., 2011; Dezdar \& Sulaiman, 2009; Doom et al., 2010; Finney \& Corbett, 2007; Sánchez \& Pérez-Bernal, 2007; Ngai et al., 2008; Shaul \& Tauber, 2012; Agaoglu et al., 2015; Tarhini et al., 2015; Peci \& Vazan, 2014.

CSF 30. Software vendor's support level: Ahmed \& Khan, 2013; Al-Fawaz et al., 2010; Dezdar \& Sulaiman, 2009; Doom et al., 2010; Ganesh \& Mehta, 2010; King \& Burgess, 2006; Kronbichler et al., 2009; Remus, 2007; Shaul \& Tauber, 2012; Norton, 2015; Agaoglu et al., 2015; Tarhini et al., 2015; Peci \& Vazan, 2014.

\subsection{Instrument Development}

A 20 -item questionnaire was developed for the purpose of collecting data both general data on interviewed persons and organizations, as well as specific data concerning ERP adoption. An integral part of the questionnaire was a list of 30 chosen CSFs, which were evaluated by respondents from two perspectives: first, we were interested in their perception of the significance of each CSF for a successful ERP adoption; second, we asked them to evaluate the extent to which these factors were met in their organizations. The survey instrument required that the respondents rate the CSFs using a 5 point scale, with items ranging from 1 (very low) to 5 (very high). In addition to these assessments, the questionnaire was used for gathering other important data related to ERP adoption (respondents' assessments of their organizations' overall ERP adoption success), with the intention to obtain control data that would enable additional correlation analysis and detection of deeper interrelationships.

This pilot questionnaire was further examined by five ERP experts, with more than 10 years of experience in the use of enterprise information systems such as SAP, Oracle, Microsoft, Epicor, IFS, Jeeves, Deacom, Sage Group, or any in-house developed ERP system, and with more than 20 ERP implementations in the private and the public sector, combined.

They provided some comments on the length and the clarity of particular questions. Their suggestions were incorporated into the final version of the questionnaire. Questionnaire validity, in terms of reliability of applied assessment scales, was additionally tested using Cronbach's test and correlation analysis. Results of the analysis pointed to a high level of reliability of both assessment scales: value of Cronbach's $\alpha$ for the scale used for assessment of CSFs' significance (A) was 0.924 , while the value of this indicator for the CSF fulfillment scale was 0.956 .

\subsection{Data Collection}

Selection of respondents in the conducted research was purposive. Purposive sampling was chosen due to the nature of the research, which required respondents with adequate knowledge, skills and experience.

The structure of respondents is given in Tab. 3, according to the following criteria: 
business area, type of ownership, number of employees, ERP software provider, employee roles, and role in project.

Tab. 4 contains data on surveyed private and public organizations' experience in ERP systems implementation. The analysis revealed that there is no statistically significant difference in experience between the private and the public sector. Therefore, it can be concluded that research results were not affected by a difference in the experience with ERP systems.
The questionnaire was administered directly, face-to-face with respondents. The face-to-face questionnaire administration technique was chosen because it was possible to clarify ambiguities which could have occurred in the completion of the questionnaire, due to its complexity. Completed questionnaires were recorded in an Excel spreadsheet, and subsequently prepared for processing in the SPSS suite.

\section{Tab. 3: Basic sample information $(\mathrm{N}=77)$}

\begin{tabular}{|c|c|c|c|c|c|}
\hline Descriptive analysis criteria & No & $\%$ & Descriptive analysis criteria & No & $\%$ \\
\hline \multicolumn{3}{|l|}{ Business area } & \multicolumn{3}{|l|}{ Number of employees } \\
\hline Industry & 28 & $36.36 \%$ & $<=100$ & 13 & $16.88 \%$ \\
\hline Public administration & 15 & $19.48 \%$ & $101-250$ & 18 & $23.38 \%$ \\
\hline Health and social care & 8 & $10.39 \%$ & $251-500$ & 16 & $20.78 \%$ \\
\hline Agriculture & 5 & $6.49 \%$ & $501-1,000$ & 10 & $12.99 \%$ \\
\hline Trade & 4 & $5.19 \%$ & $1,001-2,000$ & 10 & $12.99 \%$ \\
\hline Education & 4 & $5.19 \%$ & $>2,000$ & 10 & $12.99 \%$ \\
\hline Transportation & 2 & $2.60 \%$ & \multicolumn{3}{|l|}{ ERP Software provider } \\
\hline Finance and insurance & 1 & $1.30 \%$ & SAP & 25 & $32.47 \%$ \\
\hline Others & 10 & $12.99 \%$ & Microsoft & 8 & $10.39 \%$ \\
\hline \multicolumn{3}{|l|}{ Employee roles } & Oracle & 5 & $6.49 \%$ \\
\hline IT personnel & 42 & $54.55 \%$ & Other foreign ERP solution & 6 & $7.79 \%$ \\
\hline Managerial personnel & 26 & $33.77 \%$ & Serbian ERP solution & 33 & $42.86 \%$ \\
\hline Others & 9 & $11.69 \%$ & \multicolumn{3}{|l|}{ Role in project } \\
\hline \multicolumn{3}{|l|}{ Type of ownership } & Project managers & 17 & $22,08 \%$ \\
\hline Private & 40 & $51.95 \%$ & Key project members & 23 & $29.87 \%$ \\
\hline Public & 37 & $48.05 \%$ & Project members & 28 & $36.36 \%$ \\
\hline & & & Others & 9 & $11.69 \%$ \\
\hline
\end{tabular}

\section{Tab. 4: ERP adoption experience ( $\mathrm{N}=77)$}

\begin{tabular}{l|c|c|c|c}
\multirow{2}{*}{} & \multicolumn{2}{|c|}{ Private sector } & \multicolumn{2}{c}{ Public sector } \\
\cline { 2 - 5 } & No & $\%$ & No & $\%$ \\
\hline First ERP experience & 16 & $40.00 \%$ & 16 & $43.24 \%$ \\
\hline Not the first ERP experience & 24 & $60.00 \%$ & 21 & $56.76 \%$ \\
\hline
\end{tabular}




\subsection{Data Analysis and Interpretation of Results}

A set of procedures for data analysis was chosen with the size and type of the sample (purposeful) in mind. In accordance with its nature, the collected data was subject to quantitative analysis, by use of following analytical procedures: reliability analysis, bivariate correlations procedures, MannWhitney $\mathrm{U}$ test, K-means cluster analysis and Hodges-Lehman estimate confidence intervals.

The results obtained through data analysis served as a basis for answering the research questions.

\section{Research Results}

Data analysis described in the following text was carried out to reach answers to the research questions. In accordance with the NeumannPearson theory, statistical hypotheses and certain means for their validation were set for each research question listed in Section 1 (Tab. 5).

Analysis of average scores of CSFs significance indicates that all $30 \mathrm{CSFs}$ were recognized as important in both sectors: CSF17 (Use of steering committee for project activity control) had the lowest average score among the respondents from the public sector (4.23 out of 7 ), while CSF26 (Number of ERP modules and the dynamics of their implementation) was assessed as the least important by the respondents from the private sector, with an average score of 4.7. CSF30 (Software vendor's support level) had the highest average score among the respondents from the public sector ( 6.46 out of 7 ), while the second most significant CSF in the public sector CSF6 (Project team structure and competencies) had the greatest score in the private sector (6.45)

\section{Tab. 5: Description of the methodology used for finding answers to research questions}

\begin{tabular}{|c|c|c|c|c|}
\hline $\begin{array}{l}\text { Research } \\
\text { question }\end{array}$ & Variables & Statistical hypotheses & $\begin{array}{c}\text { Analytic } \\
\text { procedure } \\
\text { - Statistical } \\
\text { hypothesis } \\
\text { test }\end{array}$ & Results \\
\hline $\begin{array}{l}\text { Do public and } \\
\text { private sector } \\
\text { organizations } \\
\text { differ in their } \\
\text { assessments of } \\
\text { significance of ERP } \\
\text { adoption CSFs? }\end{array}$ & $\begin{array}{l}\text { Q20A: Assessments } \\
\text { of CSF's significance } \\
\text { in terms of success of } \\
\text { ERP system adoption } \\
\text { (set of } 30 \text { variables) } \\
\text { Q2: Organization } \\
\text { ownership }\end{array}$ & $\begin{array}{l}\mathrm{H}_{0} \text { : Distribution of assessments of } \\
\text { CSF's significance to the success of } \\
\text { ERP adoption does not differ between } \\
\text { public and private sector. } \\
\mathrm{H}_{1} \text { : Distribution of assessments of } \\
\text { CSF's significances the success of } \\
\text { ERP adoption differs between public } \\
\text { and private sector. }\end{array}$ & $\begin{array}{l}\text { Mann-Whitney } \\
\text { U test }\end{array}$ & $\begin{array}{l}\text { List of CSFs with } \\
\text { statistically significant } \\
\text { differences between } \\
\text { public and private } \\
\text { sector in terms of } \\
\text { assessment of their } \\
\text { significance to ERP } \\
\text { adoption success. }\end{array}$ \\
\hline $\begin{array}{l}\text { Do public and } \\
\text { private sector } \\
\text { organizations } \\
\text { differ in their } \\
\text { assessments of } \\
\text { fulfillment of ERP } \\
\text { adoption CSFs? }\end{array}$ & $\begin{array}{l}\text { Q20B: Assessments } \\
\text { of ERP adoption } \\
\text { CSFs in terms of } \\
\text { their fulfillment during } \\
\text { the ERP system } \\
\text { implementation (set of } \\
30 \text { variables) } \\
\text { Q2: Organization } \\
\text { ownership }\end{array}$ & $\begin{array}{l}\mathrm{H}_{0} \text { : Distributions of assessments } \\
\text { of CSF's fulfillment during ERP } \\
\text { implementation does not differ } \\
\text { between public and private sector. } \\
\mathrm{H}_{1} \text { : Distributions of assessments } \\
\text { of CSF's fulfillment during ERP } \\
\text { implementation differs between public } \\
\text { and private sector. }\end{array}$ & $\begin{array}{l}\text { Mann-Whitney } \\
\text { U test }\end{array}$ & $\begin{array}{l}\text { List of CSFs with } \\
\text { statistically significant } \\
\text { differences between } \\
\text { public and private } \\
\text { sector in terms of } \\
\text { assessment of their } \\
\text { fulfillment during } \\
\text { ERP implementation. }\end{array}$ \\
\hline
\end{tabular}

Note: Variable Q20A encompasses assessment of CSFs' significance, which is carried out in the context of question number 20 in the questionnaire, whereas variable Q20B encompasses assessment of the achieved level of CSFs' fulfillment in the same question. 


\section{Fig. 1: Average scores of observed CSFs' significance in the public and the private sector}

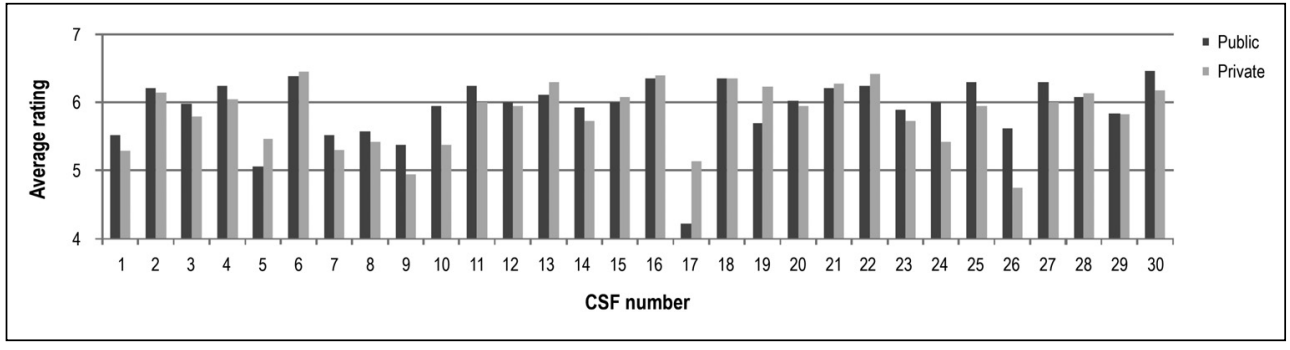

Source: own

\begin{tabular}{|c|c|c|c|c|c|c|}
\hline Tab. 6: & Results of Mann-V & ey U 1 & f CSF & gnificance & ore distri & ons \\
\hline \multirow{3}{*}{$\begin{array}{c}\text { CSF } \\
\text { (Q20A) }\end{array}$} & \multicolumn{3}{|c|}{ Mann-Whitney U test } & \multicolumn{3}{|c|}{ Hodges-Lehman median difference } \\
\hline & \multirow{2}{*}{ Mann-Whitney U } & \multirow{2}{*}{$\mathbf{Z}$} & \multirow{2}{*}{ p } & \multirow{2}{*}{ Estimate } & \multicolumn{2}{|c|}{$95 \% \mathrm{Cl}$} \\
\hline & & & & & Lower & Upper \\
\hline CSF10 & 510.500 & -2.421 & 0.015 & 1.000 & 0.00 & 1.00 \\
\hline CSF17 & 503.000 & -1.975 & 0.048 & -1.000 & -2.00 & 0.00 \\
\hline CSF19 & 525.500 & -2.148 & 0.032 & 0.000 & -1.00 & 0.00 \\
\hline CSF26 & 491.500 & -2.593 & 0.010 & 1.000 & 0.00 & 1.00 \\
\hline
\end{tabular}

Source: own

(Fig. 1). In general, it can be concluded that there are lots of similarities between the public and the private sector in terms of their average assessments of CSF significance, while major deviations can be only seen in cases of CSF17 and CSF26 (Number of ERP modules and dynamics of their implementation).

In order to avoid relying only on a subjective interpretation of the calculated average grades, the obtained assessments of CSFs' significance were analyzed using other procedures: MannWhitney $U$ test and Hodges-Lehman median difference. Mann-Whitney $U$ test of distribution has revealed (statistically) significant differences in CSF significance assessments between organizations from the two observed sectors in the cases of following CSFs: CSF10 (Completed business process redesign), CSF17 (Use of steering committee for project activity control), CSF19 (Involvement of end users in ERP adoption and implementation activities) and CSF26 (Number of ERP modules and dynamics of their implementation) (Tab. 6).
These CSFs reflect different aspects of ERP adoption: business process management, organizational culture, as well as IT/IS aspects. Hence, the results did not reveal any specific aspect of ERP adoption as an area with major differences between the two sectors, in terms of CSFs' significance assessment.

An analysis of the association of clusters formed through K-means cluster analysis of CSFs' significance scores with the variable "ownership" (Tab. 7) was conducted. In an effort to ensure best possible conclusions, clusters of organizations were formed by means of K-means cluster analysis, based on the assessments of CSF's significances. This was followed by analysis of the impact of the "ownership" variable on organizations' associations with a particular cluster (Tab. 7).

As it can be seen, organizations from the private and the public sectors are more or less evenly distributed in each of the clusters formed through cluster analysis, indicating that there are no homogenous subgroups 


\begin{tabular}{|c|c|c|c|c|}
\hline \multirow[t]{2}{*}{ Tab. 7: } & \multicolumn{4}{|c|}{$\begin{array}{l}\text { Analysis of organizations' associati } \\
\text { K-means cluster analysis of CSF sig } \\
\text { "Type of Ownership" }\end{array}$} \\
\hline & & CROS & ;STAB & Count \\
\hline \multirow{2}{*}{\multicolumn{2}{|c|}{$\begin{array}{c}\text { Cluster number } \\
\text { of case }\end{array}$}} & \multicolumn{2}{|c|}{ Ownership } & \multirow{2}{*}{ Total } \\
\hline & & Public & Private & \\
\hline Cluster 1 & & 13 & 15 & 28 \\
\hline Cluster 2 & & 3 & 4 & 7 \\
\hline Cluster 3 & & 18 & 15 & 33 \\
\hline Total & & 34 & 34 & 68 \\
\hline
\end{tabular}

with clusters formed through

$\mathrm{K}$-means cluster analysis of CSF significance scores in respect to variable "Type of Ownership"

\section{SYMMETRIC MEASURES}

\begin{tabular}{l|r|r}
\hline $\begin{array}{c}\text { Nominal } \\
\text { by nominal }\end{array}$ & Value & \multicolumn{1}{c}{$\begin{array}{c}\text { Approx. } \\
\text { sig. }\end{array}$} \\
\hline Phi & 0.091 & 0.756 \\
\hline Cramer's V & 0.091 & 0.756 \\
\hline Contingency coeff. & 0.090 & 0.756 \\
\hline N of valid cases & 68 & \\
\hline
\end{tabular}

Source: own

containing organizations from only one sector. Although the first two clusters have slightly more organizations from the public sector, while the third contains more private organizations, the value of Phi coefficient, as a measure of cohesion, clearly shows that there is no correlation between cluster affiliation and the type of organization ownership.

Slightly abandoning the primary framework and objectives of this paper, it was decided to check this correlation for other characteristics of organizations as well as assessors. Additional analyses were made in relation to the following variables: Size of the organization (number of employees) (Q4); Type of work that the assessor primarily performs (Q5); The assessor's role in the ERP system implementation project (Q6); The organization's experience in ERP system implementation (Q7); IT staff's competence (Q8) and Achievement of expected benefits from ERP system adoption (Q17).

Statistically significant differences in the structure of clusters formed on the basis of CSF's significance assessment were observed in relation to the following variables:

- The organization's experience in ERP system implementation (Q7): There is a statistically significant correlation between the membership of organizations in the clusters and "The organization's experience in the implementation of ERP systems (Q7)" (Contingency Coefficient $=.288$; Approx. Sig. = .046; Cramer's V = .301; Approx. Sig. $=.046)-$ organizations that possessed experience are dominant in cluster 1, whereas cluster 3 contains significantly more organizations with no experience in ERP system implementation than ones with experience.
- Achievement of expected benefits from ERP system adoption (Q17): There is a statistically significant correlation between the organizations' membership in a cluster and assessment of "Achievement of expected benefits from ERP system introduction (Q17)" (Contingency Coefficient $=.506 ;$ Approx. Sig. $=.001$; Cramer's V = .415; Approx. Sig. $=.001$ ) - most organizations within cluster 1 assessed that the expected benefits from the implementation of an ERP system have been achieved, whereas cluster 3 is dominated by organizations assessing that the expected benefits were "Mostly" achieved (Fig. 2).

Average scores of fulfillment of all 30 CSFs in both sectors were computed in order to reach the answer to the second research question. These average scores range from 2.5 to 4.2 , and in most cases are slightly higher in the public sector. This is a very interesting fact, which can be interpreted in numerous ways. One possible explanation is that the obtained results reflect assessors' subjectivity: assessors in the public sector may have more modest expectations, and are therefore less critical in their assessments of the achieved results. Some CSFs were recognized as challenging to fulfill in both sectors: CSF9 (Implemented performance indicator control and measurement) and CSF17 (Use of steering committee for project activity control), while some CSFs proved to be more challenging for one of the sectors: CSF1 (Completed feasibility study) is rated as much more challenging in the private sector, whereas public organizations experience more difficulties in fulfilling the 


\section{Structure of clusters formed on the basis of CSFs' significance assessment in relation to the variables "The Organization's Experience in ERP System Implementation (Q7)" and "Achievement of Expected Benefits from ERP System Adoption (Q17)"}
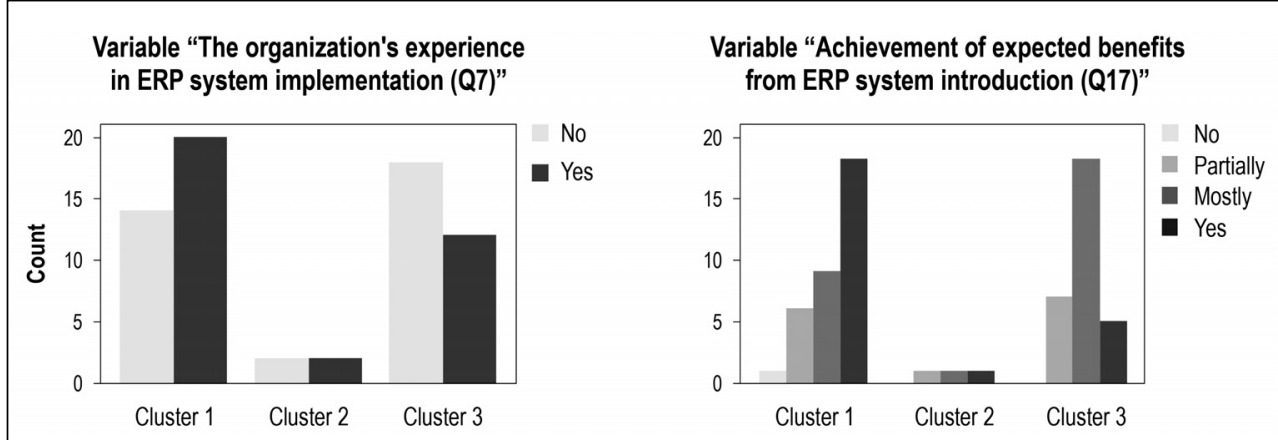

Source: own

CSF19 (Involvement of end users in ERP adoption and implementation activities). In terms of their fulfillment the highest rated CSFs (with an average above 4 ) in public sector are: CSF4 (Project coordinator or manager competency level), CSF6 (Project team structure and competencies), CSF18 (Implementation team structure and competence), CSF21 (Existence of appropriate information infrastructure and competence for use of information technologies) and CSF30 (Software vendor's support level). Contrariwise, only two CSFs received an average score of fulfillment above
4 in the private sector: CSF19 (Involvement of end users in ERP adoption and implementation activities) and CSF21 (Existence of appropriate information infrastructure and competence for use of information technologies). Overall, despite many similarities between the public and the private sector in terms of their assessment of CSF fulfillment, significant differences can be observed in the case of CSFs numbered 4, 6, 7, 19, 24 and 25 (Fig. 3).

Results of the Mann-Whitney $U$ test applied to the distributions of CSFs' fulfillment assessments have shown that differences

\section{Fig. 3: Average Assessments of CSFs' fulfillment in public and private sector}

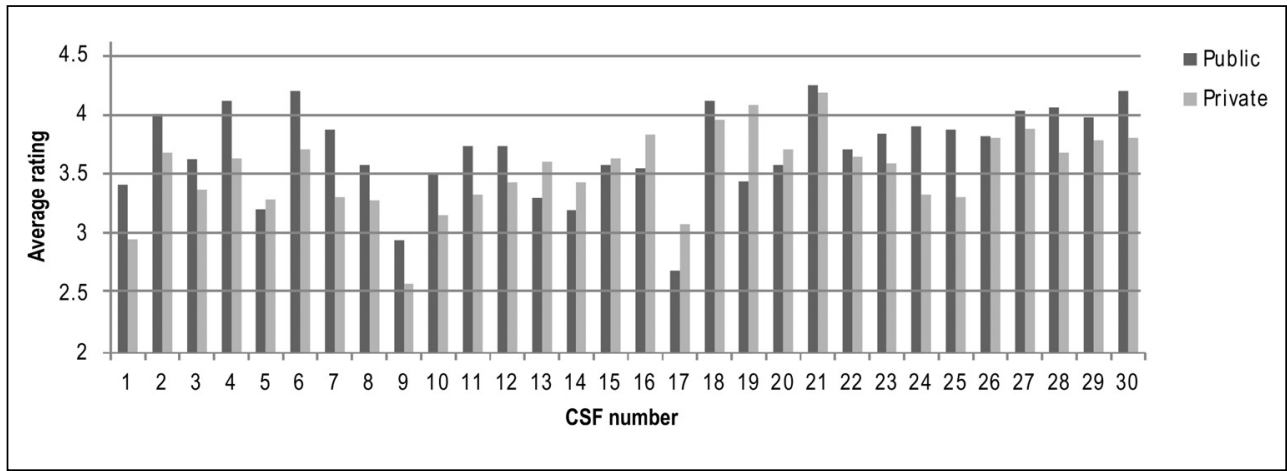


between public and private organizations are more substantial in terms of CSFs' fulfillment than they are in terms of CSFs' significance assessment. Compared to the number of CSFs with significant differences identified searching for the answer to the first research question, statistical validation of the hypothesis related to CSFs' fulfillment revealed a greater number of CSFs with significant differences between public and private organizations.

Statistically significant differences between the public and private sector were identified in the fulfillment of following CSFs (Tab. 8): CSF4 (Project coordinator or manager competency level), CSF6 (Project team structure and competencies), CSF7 (Presence of full time members on the project), CSF19 (Involvement of end users in ERP adoption and implementation activities), CSF24 (Possibility of integration of the implemented ERP solution with other software solutions in the organization) and CSF25 (Ease of use of ERP solutions and level of users' acceptance).

It is interesting that CSF19 (Involvement of end users in ERP adoption and implementation activities) is the only CSF which is identified both in the evaluation of significance and fulfillment as a CSF with significantly different scores in compared two sectors. It means that this CSF made the greatest difference between the two observed sectors in terms of their assessment of ERP adoption CSFs. This CSF was assessed as significantly more important in private sector, and at the same time, was much better fulfilled in this sector. Oppositely, CSFs numbered 9, 10, 25 and 30 are examples of CSFs that were assessed as more important and better fulfilled in public sector.

Just as with the assessments of CSFs' significance, data related to assessment of CSFs' fulfillment was subject to the examination of organizations' association with clusters formed through K-means cluster analysis in relation to "ownership" variable. As in the case of CSFs' significance evaluation, the association analysis (Tab. 9) was preceded by K-means cluster analysis with the purpose of identifying clusters with respect to the assessments of CSFs' fulfillment.

Compared with clusters formed on the basis of CSFs' significance scores, clusters formed upon CSFs' fulfillment scores have a less balanced distribution of organizations from the two observed sectors. Although the value of Phi coefficient is slightly higher than in the analysis of CSFs' significance assessments, this value still indicates that there is no correlation between cluster affiliation and the type of ownership.

In the attempt to reveal other possible correlations, additional analysis was performed with the same set of variables used in the analysis performed on clusters formed based on CSF significance assessment. Statistically significant differences in the structure of clusters formed upon CSFs' fulfillment scores were noticed in the case of the following variables:

- The assessor's role in the ERP system implementation project (Q6): There is a statistically significant correlation between organizations' membership in cluster and the type of role that assessors from these organizations had in the ERP system

Tab. 8: Results of Mann-Whitney U Test of CSFs fulfillment scores distribution

\begin{tabular}{|c|c|c|c|c|c|c|}
\hline \multirow{3}{*}{$\begin{array}{c}\text { CSF } \\
\text { (Q20B) }\end{array}$} & \multicolumn{3}{|c|}{ Mann-Whitney U test } & \multicolumn{3}{|c|}{ Hodges-Lehman median difference } \\
\hline & \multirow{2}{*}{ Mann-Whitney U } & \multirow{2}{*}{$\mathbf{z}$} & \multirow{2}{*}{$\mathbf{p}$} & \multirow{2}{*}{ Estimate } & \multicolumn{2}{|c|}{$95 \% \mathrm{Cl}$} \\
\hline & & & & & Lower & Upper \\
\hline CSF4 & 517.500 & -2.218 & 0.027 & 0.000 & 0.00 & 1.00 \\
\hline CSF6 & 528.000 & -2.284 & 0.022 & 0.500 & 0.00 & 1.00 \\
\hline CSF7 & 528.000 & -2.230 & 0.026 & 1.000 & 0.00 & 1.00 \\
\hline CSF19 & 455.500 & -3.058 & 0.002 & 0.000 & -1.00 & 0.00 \\
\hline CSF24 & 529.000 & -2.227 & 0.026 & 1.000 & 0.00 & 1.00 \\
\hline CSF25 & 554.000 & -1.977 & 0.048 & 1.000 & 0.00 & 1.00 \\
\hline
\end{tabular}




\begin{tabular}{|c|c|c|c|c|}
\hline \multirow[t]{2}{*}{ Tab. 9: } & \multicolumn{4}{|c|}{$\begin{array}{l}\text { Analysis of organizations' associatic } \\
\text { K-means cluster analysis of CSFs' fu } \\
\text { "Type of Ownership" }\end{array}$} \\
\hline & & CRO & STAB & Count \\
\hline \multirow{2}{*}{\multicolumn{2}{|c|}{$\begin{array}{c}\text { Cluster number } \\
\text { of case }\end{array}$}} & \multicolumn{2}{|c|}{ Ownership } & \multirow{2}{*}{ Total } \\
\hline & & Public & Private & \\
\hline Cluster 1 & & 20 & 14 & 34 \\
\hline Cluster 2 & & 3 & 1 & 4 \\
\hline Cluster 3 & & 10 & 20 & 30 \\
\hline Total & & 33 & 35 & 68 \\
\hline
\end{tabular}

\begin{tabular}{l|r|r}
\multicolumn{3}{c}{ SYMMETRIC MEASURES } \\
\hline $\begin{array}{c}\text { Nominal } \\
\text { by nominal }\end{array}$ & Value & \multicolumn{1}{c}{$\begin{array}{c}\text { Approx. } \\
\text { sig. }\end{array}$} \\
\hline Phi & 0.280 & 0.069 \\
\hline Cramer's V & 0.280 & 0.069 \\
\hline Contingency coeff. & 0.270 & 0.069 \\
\hline N of valid cases & 68 & \\
\hline
\end{tabular}

Source: own

implementation project (Contingency Coefficient $=.410 ;$ Approx. Sig. $=.033$; Cramer's V $=.318$; Approx. Sig. $=.033$ ) - in organizations belonging to cluster 3 , prominent members of the project team are much more represented (Fig. 4).

- Success of ERP system implementation and use (Q18): There is a statistically significant correlation between organizations' membership in cluster and the assessment of "Success of ERP system implementation and use (Q18)" (Contingency Coefficient $=.645 ;$ Approx. Sig. $=.000 ;$ Cramer's $\mathrm{V}=.597$; Approx. Sig. $=.000)-$ cluster 3 includes the most organizations that rated the success of implementation and use of an ERP system with the highest grade "Very good" (Fig. 4).

\section{Discussion and Practical Contribution}

In interpreting the results of their research associated with ERP implementation/adoption CSFs most authors point to the limitations arising from the structure of the used sample, stating that a sample made up of organizations with different characteristics could give different results. Number of employees (size), type of ownership, type of industry, and cultural differences are commonly referred to as features that can affect the research results. In this paper, our intention was to investigate to what extent does the difference in the type of ownership (public or private) affect the organizations' perception of ERP adoption CSFs' significance and success in their

\section{Fig. 4: Structure of clusters formed on the basis of CSFs' fulfillment assessment with Project (Q6)" and "Success of ERP System Implementation and Use (Q18)"}

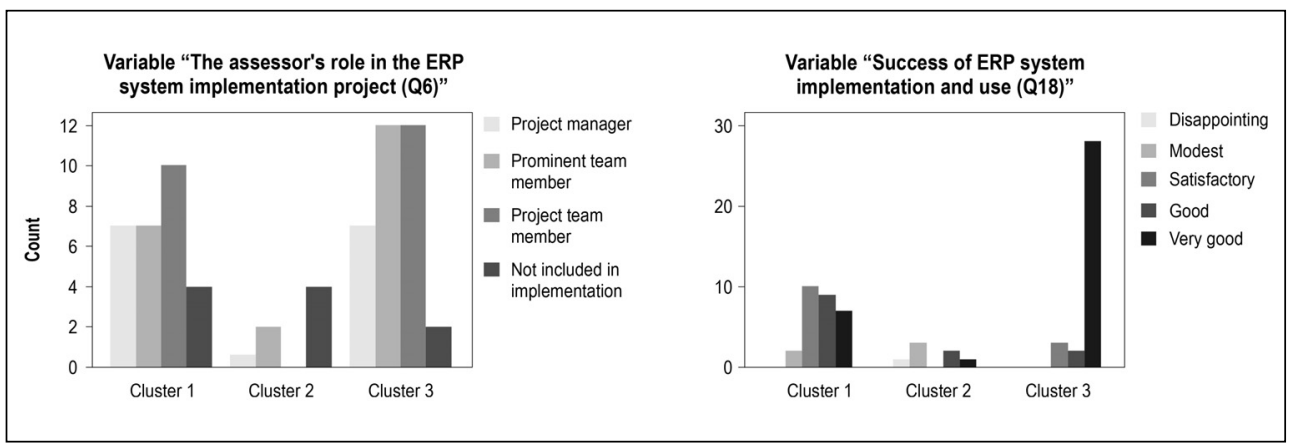


fulfillment. In order to minimize the influence of other factors, the sample was composed from organizations belonging to the same cultural milieu. When it comes to the size of the organization, the demand that organizations of different sizes should be equally represented in both observed groups (public and private sector) was taken into account in the design of the sample.

Works related to ERP adoption CSFs can be separated into two groups. Studies in the first group are aimed at discovering CSFs specific to a group of organizations with certain common characteristics. The second group of related studies comprises those focused on the determination of CSFs' significance. However, these papers generally do not differentiate the observed organizations, that is, they treat the sample as a homogenous set. Research presented in this paper is specific and demanding in many ways. It involves a comparison of two groups of organizations, which necessitates that much more attention be given to correct sample composition, as well as a greater number of respondents. Unlike other papers dealing only with the analysis of ERP adoption CSFs' significance, in this paper is further examined the effectiveness of organizations in meeting these CSFs (their fulfillment of CSFs). The authors of this paper started from the assumption that differences in the way organizations in private and public sector function may influence not only on their perception of ERP CSFs' significance (as an important criterion in the allocation of resources), but also on their success in fulfillment of these CSFs (as a measure of the efficiency of the use of allocated resources).

Research results presented in this paper indicate that differences between public and private sector organizations are more pronounced in terms of fulfillment of ERP adoption CSFs, than in their assessments of CSFs' significance. Out of 30 observed CSFs, statistically significant differences in assessments of CSFs' fulfillment were revealed in the case of 6 CSFs, while in the case of CSFs' significance assessments such differences were identified for only 4 CSFs. The most differentiating individual CSF is "Involvement of end users in ERP adoption and implementation activities (CSF19)" which is the only CSF with a recorded significant statistical difference between the two sectors for both evaluation criteria. Respondents from the private sector assessed this CSF as much more significant, and at the same time as much better fulfilled. This phenomenon can be interpreted in numerous ways, but is most surely linked with motivational factors that are obviously more present in the private sector.

It is also interesting that the perceived level of CSFs' fulfillment reached a higher average in the public sector. This is especially interesting in the light of some earlier research, which stated that ERP systems adoption is more successful in the private sector (Wingreen et al., 2014). This difference in results certainly provokes curiosity and urges us to think about the reasons. One of the possible explanations is of psychological nature, pertaining to the phenomenon when a higher level of contentment is caused by lower initial expectations. The existence of a certain type of (mostly unjustified) selfsatisfaction in the public sector is already pointed out by Wingreen et al. (2014). Another possible explanation is associated with the Serbian public sector having more experienced and skilled IT professionals, owing to the fact that the salaries were higher in the public sector until a few years ago. Another interesting finding of this paper concerns the fact that CSFs associated with management were rated as less important in the public than in the private sector, which can also be interpreted in different ways: most likely, this can be attributed to the fact that managers in public sector are less involved in EPR-related activities (they are usually delegating a significant part of their duties and responsibilities related to this endeavor to the IT staff).

The practical contribution of this research concerns some observations which should be useful for certain categories of participants in the ERP implementation/adoption process:

- From the ERP vendors' perspective important fact is that the "Software vendor's support level" (CSF30) was rated as one of the most important CSFs in both sectors, a lot more important than the "Representation of the key features of ERP system and choice of ERP solutions based on these" (CSF23). It clearly shows that the ERP vendors' commitment to the client has a greater impact on ERP adoption success than the features of ERP product itself.

- From the perspective of ERP project managers, it is interesting that CSFs 
regarded as more significant by the respondents are usually also rated better in terms of their fulfillment. Based on this fact, it can be concluded that the recognition of a CSF's significance is determinative in terms of the attention and resources devoted to the CSF, thus greatly influencing the achievement of a satisfactory level of the CSF's fulfillment. Education of ERP adoption stakeholders, especially managers, aimed at raising awareness about the importance of particular CSFs, can be crucial in preventing unsuccessful ERP adoptions.

Unlike other papers that dealt only with the assessment of CSFs' significance, this paper provides useful information on which CSFs proved to be the most challenging to fulfill in certain sectors. This information indicates which CSFs should be given special attention:

- "Implemented performance indicator control and measurement" (CSF9) is among the lowest rated in both sectors in terms of CSFs' fulfillment. Measuring the performance of any activity/process is the basis of governance, so there is no doubt that this CSF deserves a much higher degree of engagement. This observation fully coincides with the results of some recent studies, such as (Sun et al., 2015); (Shatat, 2016) and (Batada \& Rahman, 2012).

- Besides CSF9, which was rated as very poorly implemented in both sectors, other CSFs that were identified as particularly challenging for one of the sectors include: "Completed feasibility study" (CSF1) in the private sector and "Use of steering committee for project activity control" (CSF17) in the public sector. The purpose of identifying these weaknesses in particular sectors was to point out the areas on which ERP implementers/stakeholders in a particular sector should pay more attention than in the current practice.

\section{Conclusion}

The general conclusion to this research is that the differences between the public and the private sector, in terms of their perception of ERP adoption CSFs' significance, are smaller than it was initially expected. Another important observation concerns the fact that the two sectors differ more in success in fulfillment of
ERP adoptions CSFs, than their perception of the significance of particular CSFs. This fact points to the conclusion that differences in the way organizations from the public and the private sector operate greatly influence their ability to tackle problems more than their ability to recognize them.

We see this study as a pioneering venture in a deeper research on differences between private and public organizations in terms of ERP adoption CSFs. The study answered many questions, but at the same time, opened up new dilemmas. The sample was deliberately composed of organizations from the same geographical area, with the aim of eliminating the noise caused by cultural differences. However, it must be taken into account that organizations with different cultural backgrounds could have generated somewhat different signals, which could have produced somewhat different results. It would definitely be interesting to repeat this type of research on a sample comprised of organizations from different cultural milieus, since the approach to ERP adoption should not be copied from one country to another.

The initial assumption of this research was that an adoption of an ERP system by an organization, unlike implementation, can be best assessed by its employees. In line with the authors' expectations, results indicated that most respondents' prior experience is limited to one of the two compared sectors. An additional control research, conducted on a sample of ERP consultants with experience in ERP system implementation in both sectors, would reveal the impact of respondents' limited experience on the obtained research results. Although finding a sufficient number of ERP consultants with desirable experience could prove to be a challenging task, the possibility of comparing results of the present and the future research would not only provide answers to some open issues, but also greatly contribute to the reliability of future conclusions.

\section{References}

Agaoglu, M., Yurtkoru, E. S., \& Ekmekci, A. K. (2015). The effect of ERP implementation CSFs on business performance: an empirical study on users' perception. Procedia Social and Behavioral Sciences, 210, 35-42. https://doi.org/10.1016/j.sbspro.2015.11.326. 
Ahmad, M. M., \& Cuenca, R. P. (2013). Critical success factors for ERP implementation in SMEs. Robotics and Computer-Integrated Manufacturing, 29(3), 104-111. https://doi. org/10.1016/j.rcim.2012.04.019.

Ahmed, A., \& Khan, M. K. (2013). Identification of critical success factor during ERP implementation. International Journal of Science and Applied Information Technology (IJSAIT), 2(2), 12-17.

Al-Fawaz, K., Eldabi, T., \& Naseer, A. (2010). Challenges and influential factors in ERP adoption and implementation. In Online Proceedings of the 7th European Mediterranean \& Middle Eastern Conference on Information Systems. London: Brunel University.

Alves, M. C. G., \& Matos, S. I. A. (2013). ERP adoption by public and private organizations - a comparative analysis of successful implementations. Journal of Business Economics and Management, 14(3), 500-519. https://doi.org/10.3846/16111699.2011.652979.

Amini, M., \& Sadat, S. N. (2013). Critical success factors for ERP implementation. SSRN Electronic Journal, 5(16), 1-23. https://doi. org/10.2139/ssrn.2256382.

Ansarinejad, A., Amalnick, M., Ghadamyari, M., Ansarinejad, S., \& Hatami-Shirkouhi, L. (2011). Evaluating the critical success factors in ERP implementation using fuzzy AHP approach. International Journal of Academic Research, 3(1), 65-81.

Batada, I., \& Rahman, A. (2012). Measuring system performance \& user satisfaction after implementation of ERP. In Proceedings of the InSITE 2012: Informing Science + IT Education Conference (pp. 603-611). Santa Rosa: Informing Science Institute.

Campbell, J., McDonald, C., \& Sethibe, T. (2009). Public and private sector IT governance: Identifying contextual differences. Journal of Information Systems, 16(2), 5-18. https://doi. org/10.3127/ajis.v16i2.538.

Dezdar, S., \& Sulaiman, A. (2009). Successful enterprise resource planning implementation: Taxonomy of critical factors. Industrial Management \& Data Systems, 109(8), 1037-1052. https://doi.org/10.1108/02635570910991283.

Doom, C., Milis, K., Poelmans, S., \& Bloemen, E. (2010). Critical success factors for ERP implementations in Belgian SMEs. Journal of Enterprise Information Management, 23(3), 378-406. https://doi. org/10.1108/17410391011036120.
Finney, S., \& Corbett, M. (2007). ERP implementation: a compilation and analysis of critical success factors. Business Process Management Journal, 13(3), 329-347. https://doi.org/10.1108/14637150710752272.

Françoise, O., Bourgault, M., \& Pellerin, R. (2009). ERP implementation through critical success factors' management. Business Process Management Journal, 15(3), 371-394. https://doi.org/10.1108/14637150910960620.

Ganesh, L., \& Mehta, A. (2010). Critical success factors for successful enterprise resource planning implementation at Indian SMEs. International Journal of Business, Management and Social Sciences, 1(1), 65-78.

Gupta, H., Aye, K. T., Balakrishnan, R., Rajagopal, S., \& Nguwi, Y. Y. (2014). A study of key critical success factors (CSFs) for enterprise resource planning (ERP) systems. International Journal of Computer and Information Technology, 3, 813-818.

Jáčová, H., Brabec, Z., \& Horák, J. (2013). New management systems and their application through ERP systems in the Czech Republic. In Proceedings of the 11th International Conference Liberec Economic Forum (pp. 231-239). Liberec: Technical University of Liberec. Retrieved from https://dspace.tul. cz/bitstream/handle/15240/6918/24\%20231. pdf?sequence $=1$.

King, S. F., \& Burgess, T. F. (2006). Beyond critical success factors: A dynamic model of enterprise system innovation. International Journal of Information Management, 26(1), 59-69. https://doi.org/10.1016/j.ijinfomgt.2005.10.005.

Klaus, H., Rosemann, M., \& Gable, G. (2000). What is ERP? Information Systems Frontiers, 2(2), 141-162. https://doi. org/10.1023/A:1026543906354.

Kronbichler, S. A., Ostermann, H., \& Staudinger, R. (2009). A Review of critical success factors for ERP-projects. The Open Information Systems Journal, 3(1), 14-25. https://doi.org/10.2174/1874133900903010014.

Leandro, F. C. F., Mexas, M. P., \& Drumond, G. M. (2017). Identifying critical success factors for the implementation of enterprise resource planning systems in public educational institutions. Brazilian Journal of Operations and Production Management, 14(4), 529-541. https://doi.org/10.14488/BJOPM.2017.v14.n4.a9.

Leyh, C., \& Sander, P. (2015). Critical success factors for ERP system implementation projects: an update of literature reviews. In D. 
Sedera, N. Gronau, \& M. Sumner (Eds.), Lecture Notes in Business Information Processing: Vol. 198. Enterprise Systems. Strategic, Organizational, and Technological Dimensions (pp. 45-67). https://doi.org/10.1007/978-3-31917587-4 3.

Mengistie, A. A., Heaton, D. P., \& Rainforth, M. (2013). Analysis of the critical success factors for ERP systems implementation in US federal offices. In F. Piazolo, \& M. Felderer (Eds.), Lecture Notes in Information Systems and Organisation: Vol. 4. Innovation and Future of Enterprise Information Systems (pp. 183-198). https://doi.org/10.1007/978-3-642-37021-2_15.

Mohelská, H., \& Sokolová, M. (2017). Digital transparency in the public sector case study Czech Republic. E\&M Ekonomie a Management, 20(4), 236-250. https://doi. org/10.15240/tul/001/2017-4-016.

Nah, F. F., \& Delgado, S. (2006). Critical success factors for enterprise resource planning implementation and upgrade. Journal of Computer Information Systems, 47(Special Issue), 99-113.

Ngai, E. W. T., Law, C. C. H., \& Wat, F. K. T. (2008). Examining the critical success factors in the adoption of enterprise resource planning. Computers in Industry, 59(6), 548-564. https://doi.org/10.1016/j.compind.2007.12.001.

Norton, A. L. (2015). Enterprise resource planning II - A review of critical success factors. International Journal of Computer Science and Information Security, 13, 5-14.

Peci, M., \& Vazan, P. (2014). The biggest critical failure factors in ERP implementation. Applied Mechanics and Materials, 519-520, 1478-1482. https://doi.org/10.4028/www. scientific.net/AMM.519-520.1478.

Rajnoha, R., Kádárová, J., Sujová, A., \& Kádár, G. (2014). Business information systems: research study and methodological proposals for ERP implementation process improvement. Procedia - Social and Behavioral Sciences, 109, 165-170. https://doi. org/10.1016/j.sbspro.2013.12.438.

Ram, J., \& Corkindale, D. (2014). How "critical" are the critical success factors (CSFs)? Business Process Management Journal, 20(1), 151-174. https://doi.org/10.1108/BPMJ-11-2012-0127.

Remus, U. (2007). Critical success factors for implementing enterprise portals: A comparison with ERP implementations. Business Process Management Journal, 13(4), 538-552. https://doi.org/10.1109/HICSS.2006.103.
Řepa, V. (2014). Procesní management ve veřejné správě. E\&M Ekonomie a Management, 17(4), 141-158. https://doi. org/10.15240/tul/001/2014-4-011.

Rockart, J. F. (1979). Chief executives define their own data needs. Harvard Business Review, 57(2), 81-93. Retrieved from https://hbr.org/1979/03/chief-executivesdefine-their-own-data-needs.

Saade, R., \& Nijher, H. (2016). Critical success factors in enterprise resource planning implementation: a review of case studies. Journal of Enterprise Information Management, 29(1), 72-96. https://doi.org/10.1108/JEIM-032014-0028.

Sánchez, G. N., \& Pérez-Bernal, L. (2007). Determination of critical success factors in implementing an ERP system: A field study in mexican enterprises view. Information Technology for Development, 13(3), 293-309. https://doi.org/10.1002/itdj.20075.

Shatat, A. S. (2016). Critical success factors in enterprise resource planning (ERP) system implementation: An exploratory study in Oman. The Electronic Journal of Information Systems Evaluation, 18(1), 36-45.

Shaul, L., \& Tauber, D. (2012). CSFs along ERP life-cycle in SMEs: a field study. Industrial Management \& Data Systems, 112(3), 360-384. https://doi.org/10.1108/02635571211210031.

Shaul, L., \& Tauber, D. (2013). Critical success factors in enterprise resource planning systems: Review of the last decade. ACM Computing Surveys (CSUR), 45(4), 1-39. https://doi.org/10.1145/2501654.2501669.

Sommer, R. A. (2011). Public sector ERP implementation: Successfully engaging middlemanagement! Communications of the IBIMA, 2011, 1-11. https://doi.org/10.5171/2011.162439.

Sun, H., Ni, W., \& Lam, R. (2015). A stepby-step performance assessment and improvement method for ERP implementation: Action case studies in Chinese companies. Computers in Industry, 68, 40-52. https://doi. org/10.1016/j.compind.2014.12.005.

Tarhini, A., Ammar, H., Tarhini, T., \& Masa'deh, R. (2015). Analysis of the critical success factors for enterprise resource planning implementation from stakeholders' perspective: A systematic review. International Business Research, 8, 25-40. https://doi.org/10.5539/ibr. v8n4p25.

Wagner, W., \& Antonucci, Y. L. (2009). The ImaginePA project: the first large-scale, 
public sector ERP implementation. Information Systems Management, 26(3), 275-284. https://doi.org/10.1080/10580530903017401.

Wingreen, S. C., Mahdavian, M., \& Gupta, H. (2014). An investigation into enterprise resource planning implementation success: Evidence from private and public sector organizations. In Proceedings of the 18th Pacific Asia Conference on Information Systems. Atlanta: Association for Information Systems (AIS). Retrieved from http://aisel.aisnet.org/cgi/viewcontent. cgi?article $=1048 \&$ context=pacis 2014 .

Ziemba, E., \& Oblak, I. (2013). Critical success factors for ERP systems implementation in public administration. Interdisciplinary Journal of Information, Knowledge, and Management, 8, 1-19. https://doi.org/10.28945/1785.
Prof. Laslo Seres, PhD University of Novi Sad

Faculty of Economics Subotica Department of Business Informatics and Quantitative Methods

Serbia laslo.seres@ef.uns.ac.rs

Prof. Pere Tumbas, PhD University of Novi Sad

Faculty of Economics Subotica Department of Business Informatics and Quantitative Methods Serbia pere.tumbas@ef.uns.ac.rs

Prof. Predrag Matkovic, PhD University of Novi Sad

Faculty of Economics Subotica Department of Business Informatics and Quantitative Methods

Serbia

predrag.matkovic@ef.uns.ac.rs

Prof. Marton Sakal, PhD University of Novi Sad

Faculty of Economics Subotica Department of Business Informatics and Quantitative Methods

Serbia marton.sakal@ef.uns.ac.rs 


\title{
Abstract
}

\section{CRITICAL SUCCESS FACTORS IN ERP SYSTEM ADOPTION: COMPARATIVE ANALYSIS OF THE PRIVATE AND THE PUBLIC SECTOR}

\author{
Laslo Seres, Pere Tumbas, Predrag Matkovic, Marton Sakal
}

This research provides useful insight into differences in the perception of significance and the degree of fulfillment of Critical Success Factors (CSFs) of Enterprise Resource Planning (ERP) adoption between private and public sector organizations. The survey was conducted on a sample of 77 Serbian organizations, with approximately equal representation of those from the private and the public sector. A comprehensive list of CSFs, compiled as a result of an extensive literature review, was included in the questionnaire. The collected data and statistical procedures applied revealed the CSFs that differentiate the organizations from the two observed sectors. Involvement of end users in ERP adoption and implementation activities has proven to be the CSF in relation to which the assessments and attitudes of organizations from the two sectors differ the most. Results of this research indicate that differences between private and public sector organizations are more distinct in terms of their level of fulfillment of ERP adoption CSFs than they are in terms of their assessment of CSFs' significance. This points to a conclusion that differences in the way of functioning and governance of organizations from these two sectors influence their ability to tackle the problems much more than their ability to recognize them. The practical contribution of this research is in providing some useful findings that can greatly assist relevant stakeholders to achieve a higher success rate in an ERP adoption. In addition to responding to the initial research questions, this paper has also revealed new issues, suggesting the need for further research.

Key Words: ERP adoption, CSFs, private organizations, public organizations.

JEL Classification: M15.

DOI: 10.15240/tul/001/2019-2-014 